\section{Assessing the contributions of private health facilities in a pioneer private-public partnership in childhood immunization in Nigeria}

\author{
Chukwuemeka Oluoha, ${ }^{1}$ \\ Chukwuemeka Umeh, ${ }^{2}$ \\ Hycienth Ahaneku ${ }^{3}$
}

${ }^{1}$ Executive Director, Abia state Primary

Health Care Agency, Abia State, Nigeria;

2Department of International Health,

Boston University School of Public

Health, MA, USA; ${ }^{3}$ Department of

Epidemiology, University of Texas School

of Public Health, Houston, TX, USA

\section{Abstract}

The vision of Nigeria's immunization program is to reach and sustain routine immunization coverage of greater than $90 \%$ for all vaccines by 2020 . In order to achieve this, Abia state embarked on a unique private-public partnership (PPP) between private health facilities and the Abia state ministry of health. The aim of this partnership was to collaborate with private health facilities to provide free childhood immunization services in the state the first of its kind in Nigeria. This is a retrospective study of the 2011 Abia state, Nigeria monthly immunization data. In the 4 local governments operating the PPP, 45\% (79/175) of the health facilities that offered immunization services in 2011 were private health facilities and $55 \%$ (96/175) were public health facilities However, $21 \%$ of the immunization services took place in private health facilities while $79 \%$ took place in public health facilities.

Private health facilities were shown to have a modest contribution to immunization in the 4 local governments involved in the PPP. Efforts should be made to expand PPP in immunization nationally to improve immunization services in Nigeria.

\section{Introduction}

In order to achieve the national vision of reaching and sustaining routine immunization coverage of $90 \%$ for all vaccines by the year $2020,{ }^{1}$ there was need to involve both the private and public health facilities in providing immunization services. There is paucity of information on the success of private-public partnership in improving free immunization coverage in Africa. ${ }^{2}$ However, in tuberculosis
(TB) management, private-public partnership has been shown to have contributed in detecting more than $25 \%$ of TB cases in China, India, Nigeria and Philistines and in maintaining a high treatment among TB patients. ${ }^{3}$

Utilization of private health facilities is common in Nigeria. ${ }^{4}$ In some towns; the private sector had outgrown the public sector in health care provision. A study in Nigeria showed that $78 \%$ of people treated their last case of diarrhea and $65 \%$ treated their last case of acute respiratory infection outside the public health sector. ${ }^{4}$ This preference for private health facilities might be due to proximity of private health facilities to the people, ability to have a flexible payment schedule, constant availability of a medical doctor in private health facilities and poor services in some government hospitals. ${ }^{5}$ This preference for health facilities informed the need to bring in the private sector into the immunization program while maintaining the high quality of services provided.

The realization of the importance of the private health facilities in meeting the immunization target while maintaining the quality of care led to the signing of a memorandum of understanding (MOU) in 2009 between the Abia state Ministry of Health (MOH) and private health facilities. The MOU sought to formally involve private health facilities in the provision of free immunization services in the state. The collaboration involves: i) supply of free vaccines to private health facilities; ii) provision of cold chain equipment to ensure vaccines are potent; iii) provision of data tools e.g. tally sheets, registers etc.; and iv) capacity building for the private service providers. On their part, the private health facilities are to: i) provide the vaccination free to clients; ii) record immunization data and render monthly data returns as required; iii) collect vaccines from local government areas (LGAs) cold store and account for all vaccines and materials collected; iv) provide weekly scheduled routine immunization services, and v) allow access to $\mathrm{MOH}$ officers or its agents to enter their facilities for purposes of supervision, surveillance, monitoring and evaluation.

The private-public partnership was open to all private health facilities in Abia state, but is mainly functional in four local governments areas of Aba South, Aba North, Osisioma and Umuahia North. These four local government areas are urban/semi-urban LGAs and have many private health facilities operating within them. This private-public partnership (PPP) is unique because the private facilities provide the services free without being paid any money by government or development partners. Our literature search did not reveal any documented evidence of this type of partnership in any other part of Africa. The PPP in childhood immunization being practiced in places like
Correspondence: Chukwuemeka Anthony Umeh, 59 Babaponmile Street, Onipetesi Estate, Ikeja Lagos, Nigeria.

Tel. +2348086992636 .

E-mail: emmyumeh@bu.edu

Key words: childhood, immunization, privatepublic partnership, Nigeria.

Contributions: CO conceived the idea of the study. All the authors were jointly responsible for data sorting, data analysis, manuscript writing and editing. All authors have seen and approved the final version of the manuscript.

Conflict of interests: Chukwuemeka Oluoha is a member of the staff of Abia State Ministry of Health.

Acknowledgements: we wish to thank Dr Aseme, the Abia state immunization officer, Mr John Onwugbufor, and all the staff of primary health care department ministry of health for their immense contributions in obtaining the immunization data.

Received for publication: 5 November 2012 . Revision received: 12 June 2013.

Accepted for publication: 26 November 2013.

This work is licensed under a Creative Commons Attribution NonCommercial 3.0 License (CC BYNC 3.0).

(C) Copyright C. Oluoha et al., 2014

Licensee PAGEPress, Italy

Journal of Public Health in Africa 2014; 5:297

doi:10.4081/jphia.2014.297

Senegal, Bangladesh etc. were those in which the government contracted out immunization services to private health facilities. ${ }^{6}$ This study seeks to assess the contribution of the private health facilities in providing immunization services in these four local government areas.

\section{Materials and Methods}

This is a retrospective study of data submitted monthly by the local government immunization officers to the Primary Health Department of Abia State Ministry of Health between January 1, 2011 and December 31, 2011

The local government immunization officers collect vaccines from the state cold store and store them in the local government cold stores. The health facilities then collect their vaccines from the local government cold stores. However, some large tertiary hospitals collect their vaccines directly from the state cold store. The health facilities supply data monthly to the local government immunization offi- 
cers (LIOs) on vaccines and consumables (syringes, injection water) used. The LIOs submit the data monthly to the Primary Health Department of $\mathrm{MOH}$.

The data from the local government immunization officers contains the names of the different health facilities, the status of the health facility (whether private or public), and the number of children that received the different vaccines in each of the health facilities. The data also contains the number of children that received different doses of each of the vaccines in each health facility. For instance, for diphtheria-pertussis-tetanus (DPT) vaccine, the number of children that received the first dose, the second dose and the third dose of DPT vaccine are all indicated in separate columns. We used the third dose of DPT (DPT3) which is usually given at 14 weeks to measure the routine immunization coverage in the local government areas because unlike some other vaccines, DPT is not given during supplementary immunization activities and is a more accurate indicator of vaccines given through routine immunization. ${ }^{7}$

The estimated local government population is based on the 2006 population census with an annual growth rate of $2.7 \% .^{8}$ The number of births a year is estimated as $4 \%$ of the population. The estimated monthly birth cohort is the estimated yearly number of births divided by $12 .{ }^{9}$

Abia state, like other states in Nigeria, operates the expanded program on immunization with five prescribed visits to receive one dose of Bacille Calmette Guerin, four doses of oral polio virus vaccine, three doses of DPT, three doses of hepatitis $B$ vaccine, one dose of measles and yellow fever vaccines. ${ }^{1,10}$

\section{Results}

The result in Table 1 showed that in Aba North, 74\% (28/38) of the health facilities that offered immunization services in 2011 were private health facilities and $26 \%$ (10/38) were public health facilities. However, $40 \%$ of the immunization services took place in private health facilities while $60 \%$ took place in public health facilities.

In Umuahia North, $20 \%$ (10/50) of the health facilities that offered immunization services in 2011 were private health facilities and $80 \%$ (40/50) were public health facilities. A percentage of $13 \%$ of the immunization services took place in private health facilities while $87 \%$ took place in public health facilities (Table 1). Furthermore, in Aba South, $53 \%$ (26/49) of the health facilities that offered immunization services in 2011 were private health facilities and $47 \%$ (23/49) were public health facilities. However, $24 \%$ of the immunization services took place in private health facilities while $76 \%$ took place in public health facilities (Table 1).

In Osisioma, $39 \%(15 / 38)$ of the health facilities that offered immunization services in 2011 were private health facilities and $61 \%$ (23/38) were public health facilities. However, $15 \%$ of the immunization services took place in private health facilities while $85 \%$ took place in public health facilities (Table 1).

In summary, in the four local governments, $45 \%(79 / 175)$ of the health facilities that offered immunization services in 2011 were private health facilities and $55 \%(96 / 175)$ were public health facilities. However, $21 \%$ of the immunization services took place in private health facilities while $79 \%$ took place in public health facilities.

\section{Discussion}

The PPP has been beneficial in providing immunization services to most parts of these four local government areas involved in the PPP. Forty five percent of the health facilities offering immunization in these four local government areas are private facilities. This has helped to get the health facilities closer to the people and has also helped to provide improved access to immunization for families that prefer patronizing private health facilities. Distance from health facilities has been shown as a barrier to accessing routine immunization by caregivers. ${ }^{11,12}$

Although $45 \%$ of the health facilities offering immunization are private facilities, only $21 \%$ of the immunization services occur in these facilities. This is compared to $22 \%$ of immunization delivered by non-profit private sector facilities in urban areas in Bangladesh. ${ }^{13}$ In Ghana, it is estimated that $40 \%$ of total immunization are delivered by non-profit civil society organizations and mission hospitals through their outreaches and community based outreaches. ${ }^{13}$ The large proportion of immunization in public health facilities in Abia state could be due to the fact that some of the public health facilities are large general hospitals, and teaching hospitals that have large clientele and serve as referral hospitals. In addition, many people might not yet be aware that some nearby private health facilities provide immunization services and so still travel far to public health facilities to immunize their children. Furthermore, public health facilities carry out immunization outreach activities to neighboring communities and immunize children at their homes and communities and this increases the number of

Table 1. Showing immunization services in different health facilities in Abia state, Nigeria.

\begin{tabular}{|c|c|c|c|c|c|}
\hline $\begin{array}{l}\text { Local government } \\
\text { area }\end{array}$ & $\begin{array}{l}\text { Estimated } \\
\text { population }\end{array}$ & $\begin{array}{l}\text { Estimated monthly } \\
\text { birth cohort }\end{array}$ & $\begin{array}{l}\text { Type of health } \\
\text { facility }\end{array}$ & $\begin{array}{l}\text { Number of health facilities } \\
\text { offering immunization services }\end{array}$ & $\begin{array}{l}\text { Total number } \\
\text { immunized in } 2011\end{array}$ \\
\hline Aba North & 119,575 & 409 & $\begin{array}{l}\text { Private } \\
\text { Public } \\
\text { Total }\end{array}$ & $\begin{array}{l}28(74 \%) \\
10(26 \%) \\
38\end{array}$ & $\begin{array}{l}1362(39.60 \%) \\
2081(60.40 \%) \\
3443\end{array}$ \\
\hline Umuahia North & 245,474 & 840 & $\begin{array}{l}\text { Private } \\
\text { Public } \\
\text { Total }\end{array}$ & $\begin{array}{l}10(20 \%) \\
40(80 \%) \\
50\end{array}$ & $\begin{array}{l}832(12.70 \%) \\
5742(87.30 \%) \\
6574\end{array}$ \\
\hline Aba South & 471,516 & 1614 & $\begin{array}{l}\text { Private } \\
\text { Public } \\
\text { Total }\end{array}$ & $\begin{array}{l}26(53 \%) \\
23(47 \%) \\
49\end{array}$ & $\begin{array}{l}2718(24.30 \%) \\
8446(75.70 \%) \\
11,164\end{array}$ \\
\hline Osisioma & 244,330 & 836 & $\begin{array}{l}\text { Private } \\
\text { Public } \\
\text { Total }\end{array}$ & $\begin{array}{l}15(39 \%) \\
23(61 \%) \\
38\end{array}$ & $\begin{array}{l}1295(15 \%) \\
7361(85 \%) \\
8656\end{array}$ \\
\hline Total & & & $\begin{array}{l}\text { Private } \\
\text { Public } \\
\text { Total }\end{array}$ & $\begin{array}{l}79(45 \%) \\
96(55 \%) \\
175\end{array}$ & $\begin{array}{l}6207(20.80 \%) \\
23,630(79.20 \%) \\
29,837\end{array}$ \\
\hline
\end{tabular}


people that are immunized by the public health facilities unlike most of the private health facilities that only immunize at their facilities.

In 2010, the mean DPT3 coverage was 95\% in the 4 PPP LGAs and 59\% in the other 13 LGAs (target 80\%). This is compared to the overall national coverage of $68 \%$ in Nigeria. ${ }^{7}$ This discrepancy in immunization coverage between PPP local governments and other local government areas might be due to the fact that health facilities offering immunization services might be more easily accessible to people in PPP local governments. Contracting services to non-profit non-governmental organizations has also been showed to improve access to immunization and other primary health care services in Bangladesh, Cambodia, Senegal etc. ${ }^{6}$ However, unlike the case of Abia state, these non-profit organizations were paid to carry out these services.

The data also showed wide variations in the proportion of facilities in each of the local government areas that offered immunization services which were privately owned. While $74 \%$ and $53 \%$ of facilities offering immunization in Aba North and Aba South local government areas respectively were privately owned, only $20 \%$ were privately owned in Umuahia North. This could be explained by the fact that Aba North and Aba South are commercial cities with a lot of private facilities and few public health facilities while Umuahia is the state capital with a lot of public health facilities.

One limitation of this public-private partnership is that all the local government areas actively involved in this partnership are urban or semi-urban. Thus the findings from this study cannot be generalized to rural local government areas which usually have fewer privately owned health facilities.

\section{Conclusions}

Private health facilities have been shown to have a modest contribution to immunization in the four local governments practicing the
PPP. In addition, they have also helped to make routine immunization accessible in most parts of the local governments involved in the PPP. Efforts should be made to expand this PPP in immunization nationally to improve immunization services in Nigeria. Similar partnership could also prove beneficial in other African countries.

However, there is need to ensure that the potency of vaccines are maintained by an effective monitoring of the cold chain system and that staff at the private health facilities are regularly trained. This is because private health facilities have been shown to lack knowledge on immunization schedule, waste and vaccine management and lack correct cold chain equipment. ${ }^{14,15}$

\section{References}

1. National Primary Health Care Development Agency (NPHCDA). National immunization policy - revised 2009. Abuja: NPHCDA; 2009. Available from: http://www.thephss.org/ppep/resource/Nati onal_Immunization_Policy_with_frwd_an d_acknwldg.pdf Accessed: July 18, 2012.

2. Levin A, Kaddar M. Role of the private sector in the provision of immunization services in low- and middle-income countries. Health Policy Plan 2011;26:i4-12.

3. Lal SS, Uplekar M, Katz I, et al. Global Fund financing of public-private mix approaches for delivery of tuberculosis care. Trop Med Int Health 2011;16:685-92.

4. Bustreo F, Harding A, Axelsson H. Can developing countries achieve adequate improvements in child health outcomes without engaging the private sector? Bull World Health Organ 2003;81:886-95.

5. Chukudebelu W, Ikeme A, Okaro J, et al. Involving the private sector in improving obstetric care, Anambra State, Nigeria. Int J Gynecol Obstet 1997;59:S107-12.

6. Sadoh AE, Eregie CO. Timeliness and completion rate of immunization among
Nigerian children attending a clinic-based immunization service. J Health Popul Nutr 2009;27:391-5.

7. Centers for Disease Control and Prevention (CDC). Morbidity and Mortality Weekly Report (MMWR). Progress toward poliomyelitis eradication - Nigeria, January 2010-June 2011. Weekly 2011;60:1053-7. Available from: http:// www.cdc.gov/mmwr/preview/mmwrhtml/m m6031a3.htm Accessed: July 20, 2012.

8. United Nations Population Fund (UNFPA) Nigeria. UNFPA in Abia state. Available from: http://nigeria.unfpa.org/abia.html Accessed: September 15, 2012.

9. World Bank. Birth rate, crude (per 1,000 people). Available from: http://data.worldbank.org/indicator/SP.DYN.CBRT.IN Accessed: August 12, 2012.

10. Babalola S. Maternal reasons for nonimmunisation and partial immunisation in northern Nigeria. J Paediatr Child Health 2011;47:276-81.

11. Oladokun RE, Adedokun B0, Lawoyin TO. Children not receiving adequate immunization in Ibadan, Nigeria: what reasons and beliefs do their mothers have? Niger J Clin Pract 2010;13:173-8.

12. Bass AG. A review to identify the role of civil society organizations in immunization. Prepared for the GAVI Secretariat and the GAVI CS Task Team; May 2006.

13. Liu X, Hotchkiss DR, Bose S. The effectiveness of contracting-out primary health care services in developing countries: a review of the evidence. Health Policy Plan 2008;23:1-13.

14. Soeung SC, Grundy J, Morn C, Samnang C. Evaluation of immunization knowledge, practices, and service-delivery in the private sector in Cambodia. J Health Popul Nutr 2008;26:95-104.

15. Ouedraogo A. Etude sur l'apport des structures sanitaires privees a la vaccination de routine. Rapport de mission. Ministry of Health/European Union, Islamic Republic of Mauritania; 2003. 